\title{
REVIEW
}

\section{Pacemaker lead complications: when is extraction appropriate and what can we learn from published data?}

\author{
F A Bracke, A Meijer, L M van Gelder
}

Indications for extraction of chronically implanted pacemaker leads have been classified as mandatory, necessary, or discretionary. ${ }^{12}$ In published reports as well as in clinical practice, most indications cited are non-vital. These indications are often based on clinical judgement, even in published policy statements. ${ }^{3} \mathrm{We}$ therefore reviewed published work on this subject, starting from the Pubmed database, in an attempt to provide an evidence base for the benefits of lead extraction. We begin with a brief overview of the results and complications of current extraction techniques.

\section{Lead extraction}

Recently, comprehensive endovascular techniques have been developed for pacemaker lead extraction. ${ }^{245}$ In the superior vena cava approach, a locking stylet is introduced into the lead and locked close to the distal electrode in order to apply traction directly to the tip. ${ }^{6}$ If gentle traction is not successful, telescoping sheaths can be advanced over the lead to disrupt fibrous binding of the lead to veins or myocardium. When necessary, the tip of the lead is freed by countertraction, the sheath being positioned against the myocardium to prevent inversion during traction on the lead. Recently, a laser sheath has been introduced which uses photoablation to disrupt the fibrous bindings instead of mechanical force. ${ }^{7-10}$

In the transfemoral approach, the pacing lead is grabbed with a deflecting guide wire or retriever through a long sheath inserted from the femoral vein. ${ }^{71}$ The proximal end of the lead is pulled down from the subclavian vein. Then the outer sheath is advanced over the lead to disrupt the scar tissue, as with the superior approach. When the myocardium is reached countertraction is applied.

Table 1 Results of major studies of pacemaker lead extraction

\begin{tabular}{|c|c|c|c|c|c|}
\hline \multirow[b]{3}{*}{ Author } & \multicolumn{5}{|l|}{ Technique } \\
\hline & \multirow{2}{*}{$\begin{array}{l}\begin{array}{l}\text { Locking stylets } \\
\text { only }\end{array} \\
\text { Alt et } a l^{6}\end{array}$} & \multicolumn{2}{|c|}{$\begin{array}{l}\text { Conventional counter traction with } \\
\text { telescoping sheaths }\end{array}$} & \multicolumn{2}{|c|}{ Laser assisted counter traction } \\
\hline & & Smith et al ${ }^{11}$ & Byrd et al ${ }^{12}$ & Kennergren $^{9}$ & Reiser $e t a l^{10}$ \\
\hline Number of patients & 105 & 1299 & 2338 & 149 & 1463 \\
\hline Number of leads extracted & 150 & 2195 & 3540 & 179 & 2249 \\
\hline Complete extraction (\%) & 81 & 86.8 & 93 & 89.5 & 90 \\
\hline Partial extraction (\%) & 12 & 7.5 & 5 & 6 & 3 \\
\hline Failure (\%) & 7 & 5.8 & 2 & 4.5 & 7 \\
\hline Major complications (\%) & 0 & 2.5 & 1.4 & 0.6 & 3.3 \\
\hline Death $(\%)$ & 0 & 0.6 & 0.04 & 0 & 0.8 \\
\hline
\end{tabular}

Table 1 summarises the results of the different extraction techniques. With the use of only locking stylets, Alt et al achieved total removal of $81 \%$ of 150 leads, partial removal of $12 \%$, and failure in $7 \%{ }^{6}$ There were no major complications. In the US lead extraction database, extraction was attempted with either a convencomplications occurred in $2.5 \%$ of the 1299 patients. Eight patients died $(0.6 \%)$. In a paper describing experience with lead extraction between 1994 and 1996, Byrd et al reported complete removal in 93\%, and partial removal in $5 \%$ of 3540 leads. Major complications occurred in $1.4 \%$, including one fatality. ${ }^{12}$

In a randomised trial, a laser sheath achieved $94 \%$ complete removal of the lead against $64 \%$ with conventional sheaths during initial attempts at extraction of 465 chronically implanted leads. ${ }^{8}$ In a registry of laser sheath extraction in 1463 patients, complete success was achieved in $90 \%$ of 2249 patients and partial success in $3 \%{ }^{10}$ There were complications in $3.4 \%$ of patients, including tamponade (1.4\%) and haemothorax $(0.3 \%)$. Twelve patients died $(0.8 \%)$, mostly as the result of tamponade.

Byrd et al reported an increased risk of failed or partial extraction with increasing implant duration (doubling every three years). ${ }^{12}$ Implant duration was not linked to complications in any of the cited papers. However, major complications of extraction of 2732 Accufix leads (Telectronics Pacing Systems Inc, Englewood, Colorado, USA), reported by the Accufix Research Institute on www.accufix.com, increased from $2 \%$ at one year implant duration to $8.3 \%$ with an implant duration of tional superior or an inferior approach. ${ }^{11} \mathrm{Com}-$ plete removal was achieved in $86.8 \%$ and partial removal in $7.5 \%$ of 2195 leads. Major
Death (\%)
Department of Cardiology, Catharina Hospital, PO Box 1350, 5602 ZA Eindhoven, Netherlands

F A Bracke

A Meijer

LM van Gelder

Correspondence to: Dr Bracke

f.bracke@skynet.be

Accepted 25 October 2000 
more than five years. Physician's lack of experience, increasing numbers of leads extracted, and female sex have, however, been associated with an increased risk of complications. ${ }^{11}{ }^{12}$

\section{Infection}

There are no randomised studies comparing lead extraction with a conservative strategy aimed at salvaging the leads and the generator. Some reports have compared both treatment options in a large patient population from a single centre.

Lewis et al described 75 patients (including 10 with epicardial systems) presenting with pocket abscess or erosion, including 17 patients with positive blood cultures. ${ }^{13}$ From 32 patients treated conservatively (antibiotics, limited debridement, and irrigation or aspiration of the infected site) only one patient was cured. In the other 43 patients, primary removal of all hardware led to successful resolution of infection in all. Also, the 31 patients who failed conservative treatment were cured after removal of the pacing system. Molina reported the outcome of infection in 21 pacemaker and 17 defibrillator patients. ${ }^{14}$ Infection persisted in all 12 patients treated with antibiotics only (including two deaths). Primary removal of leads and generator in 26 patients cured all of them. These data are supported by reports of primary removal of the pacing system. Brodman et al had a successful outcome in 41 of 42 patients in whom all hardware was removed. ${ }^{15}$ One patient died postoperatively because of persistent sepsis from a retained lead segment. Klug et al tried to remove all material either endocardially or surgically in 52 patients with pacemaker related endocarditis. ${ }^{16}$ Two patients died after surgical treatment. Infection reoccurred in two patients, and three patients died late after the procedure with symptoms of an infective syndrome.

Although successful conservative treatment of infection is described in many case reports, only a few papers mention success in a substantial number of patients. Hurst et al described successful eradication of infection in 19 patients with infection limited to the pacemaker pocket or skin erosion. ${ }^{17}$ Treatment consisted of extensive debridement and generous enlargement of the pocket to ensure adequate closure without tension. The pocket was irrigated with a closed irrigation system containing antibiotics and tyloxapol. Garcia-Rinaldi et al successfully relocated the generator to a deeper subfascial plane in the abdominal wall in 10 patients with exposed pacemakers without gross signs of infection. ${ }^{18}$

It can be concluded that total removal of the pacemaker system is the most reliable way of eradicating any pacemaker related infection, and most clinicians agree on extraction in the event of systemic infection. Attempts at conservative treatment should be limited to patients presenting with skin erosions or low grade pocket infection. If chosen, relocation of the pacemaker to a deeper plane is advisable, along with careful attention to alleviating skin erosion by any hardware. If the attempt at conservative treatment fails, complete extraction is advised.

Whenever extraction is attempted, complete removal of the pacing system is important. Per- sistence of infection has been described in $17-77 \%$ of patients in whom only the generator was removed. ${ }^{19-22}$ With this approach, Parry et al reported three deaths among 53 patients and Rettig et al four deaths among 21 patients.

Failure to extract the entire lead can lead to persisting infection. Lewis et al needed to do a thoracotomy to remove a retained lead segment in three of four patients with failed endovascular extraction before infection was controlled. ${ }^{13}$ Molina had to reoperate on two patients with a retained lead before infection was controlled. ${ }^{14}$ There is also concern in pacemaker related endocarditis over embolisation of vegetations adhering to the lead when endovascular extraction is attempted. Klug et al removed leads intravascularly in 38 patients with vegetations of less than $10 \mathrm{~mm} .{ }^{16}$ Although pulmonary scintigraphy in 33 patients showed a 30\% new embolisation rate, these were without clinical sequelae. Surgical extraction was performed in 10 patients with larger vegetations. In this group, two deaths occurred after septic complications. This is an argument for expanding endovascular lead removal to include patients with larger vegetations, as there is no evidence of a deleterious effect of endovascular extraction compared with surgical extraction.

It is useful to reconsider the indication for pacing after successful extraction of the infected pacing system. Discontinuation of pacemaker treatment after lead extraction is reported in $13-52 \%$ of patients. ${ }^{13}{ }^{23}{ }^{24}$ In these patients, there is no advantage in salvaging a non-used pacing system.

\section{Risk of venous occlusion}

Meyers et al and Byrd et al stated that if too many leads are present, the resultant reaction has a high probability of obliterating the vein. ${ }^{12}$ As it is, non-functional leads make up $31-40 \%$ of indications for lead extraction. ${ }^{6}{ }^{11} 12$

However, abandoned non-infected leads, with the wires insulated and the lead securely fastened to the fascia, have a very low complication rate. Furman et al and Parry et al reported complications in, respectively, one of 152 and two of 119 patients with abandoned leads. ${ }^{2125}$ In a recent prospective study, de Cock et al found no differences with respect to thrombotic complications in 48 patients with multiple leads (39 patients with three leads, nine with four leads) versus 48 age matched control patients with dual chamber pacemakers. ${ }^{26}$ Of all phlebographic studies, only Pauletti et al described an increased incidence of occlusion with multiple (mostly two) leads compared with single leads $(26 \% v 8 \%) .^{27-33}$

In contrast to an incidence of between $8 \%$ and $21 \%$ of occlusion of the subclavian or brachiocephalic vein in these studies, the incidence of pacemaker induced superior vena cava syndrome is reported to be very low, at $0.03-0.4 \% .^{34-36}$ In a review by Mazetti et al reporting 37 cases of superior vena caval obstruction, only five patients had one or more abandoned but intact leads. ${ }^{36}$ Thus it is unlikely that properly abandoned leads are a prime risk factor for occlusion. 
It is important to realise that in contrast to an intact abandoned lead, infected or severed leads after failed extraction attempts do constitute a risk factor for venous occlusion. Infection was present in $30 \%$ and a severed lead in $43 \%$ of the 37 patients described by Mazetti et al, including nine with both infection and a severed lead. ${ }^{36}$ Zerbe et al reported superior vena cava syndrome in two patients after previous extraction attempts. ${ }^{37}$ Mitrovic et al performed phlebography in 12 patients with right sided severed leads in whom the free distal end was left unsecured intraluminally. ${ }^{30}$ Complete superior vena caval obstruction was observed in two patients, all others having an occluded brachiocephalic or subclavian vein. In contrast, only 15 of 100 consecutive patients with normal functioning leads had venous occlusion.

In conclusion, there is no evidence that properly abandoned leads are a risk factor for venous occlusion and they should not be routinely extracted. Although an argument is sometimes made that an "excessive" number of leads will inevitably give rise to complications, there is no published evidence to support this. Further investigation into the natural history of patients with multiple leads, and also into the thrombogenicity of the extraction procedure itself, is necessary before lead extraction can be considered beneficial with any number of leads present.

Although there are no reports specifically addressing non-functional leads in young patients, special considerations may apply to this population-for example, the likely need for multiple implants in the future, long implant duration, and small body size. From the viewpoint of lead extraction, timely extraction may increase the success rate and avoid the complications of having to extract multiple leads with a longer implant duration in the future. In particular, the lack of proof that abandoned leads are harmful does not justify indiscriminate extraction of non-functional leads, even in young patients. Furthermore, a smaller body size may increase the risks of lead extractionthe higher complication rate described in female patients could well be related to body size, so the same may also be true for young patients. ${ }^{11}{ }^{12} \mathrm{~A}$ sensible approach therefore may be to extract only leads with a short implant duration using technology adapted to the body size.

An exception to this recommendation may be pacemaker related venous obstruction, where lead extraction can result in recanalising the occlusion. Ing et al first extracted the malfunctioning lead that caused superior vena caval or innominate vein obstruction in two patients. $^{38}$ They then passed a guide wire through the obstruction and dilated and stented the vein, after which they implanted a new lead. We used a laser sheath in three patients with venous occlusion to extract dysfunctional leads and cross the obstruction. ${ }^{39}$ We then inserted a guide wire beyond the obstruction to secure access to the central venous circulation before removing the sheaths. Subsequently, new leads were implanted by the same route. In this way, the risk of bilateral occlusion is avoided and the contralateral site is saved as an entry point in case of future complications.

Although Seeger and Scherer showed new pulmonary emboli on pulmonary scintigraphy after pacemaker implantation in three of 20 patients not treated with anticoagulation, ${ }^{40}$ clinically evident pulmonary embolism is rare-only one of 520 patients in the report by Porath et al..$^{41}$ Furthermore, other predisposing factors are often present. ${ }^{42}$ Anticoagulation is usually sufficient to prevent further embolisation. $^{41-45}$ However, if embolisation persists despite anticoagulation, the mortality can reach $75 \%$ if the lead is not removed. ${ }^{41}$

\section{Accufix and Encor leads}

Protrusion of a fractured J shaped retention wire of Accufix and Encor bipolar atrial leads (Telectronics Pacing Systems) has been implicated as the cause of death in only six of 30357 patients. The probability of remaining free of injury is $99.9 \%$ at five years after implantation, the rate of injury being linear or decreasing slightly as time from implant increases. ${ }^{46}$ However, lead extraction might have prevented injury in high risk patients: eight years after implantation, only $40 \%$ of the surviving population still had the Accufix lead in place. ${ }^{47}$ On the other hand, major complications of lead extraction-including 15 fatalities-occurred in $4.5 \%$ of 4076 patients. ${ }^{48}$ Also, as reported by the Accufix Research Institute on www.accufix.com, major complications of extraction increased from $2 \%$ at one year of implant duration to $8.3 \%$ with an implant duration of more than five years.

In conclusion, if the retention wire is intact, serial fluoroscopy to screen for the integrity of the J wire is appropriate. Extraction is advised if the $\mathrm{J}$ wire is protruding or has migrated, as this has the highest potential to cause injury. In patients with a suspected fracture and a longer life expectancy, extraction can also be advised. In elderly patients or those with serious comorbidity, serial screening can be an alternative in this instance. Where elderly patients present with a protruded or migrated J wire, decisions should be made on a case by case basis.

\section{Miscellaneous}

Endocardial leads inadvertently implanted in the left ventricular cavity should be removed immediately after implantation. If already chronically implanted, anticoagulation is reported to be efficient as primary or secondary prevention of cardioembolic stroke, although some authors prefer extraction. ${ }^{249-51}$ In our opinion, extraction should be reserved for recurrent embolisation occurring despite adequate anticoagulation, or where anticoagulation cannot be used. A surgical approach is preferred because of the risk of systemic embolisation with advancement of sheaths over the lead, even though Trohman et al described percutaneous extraction in a patient on chronic warfarin treatment without complications. ${ }^{52}$

Tricuspid valve insufficiency is sometimes cited as an indication for lead extraction. ${ }^{83}$ However, the outcome of extraction on valvar function is never mentioned. ${ }^{8}$ Furthermore, we 
Table 2 Indications for pacemaker lead extraction

Infection

Systemic infection or pacemaker lead related endocarditis: primary lead extraction

Local infection: primary lead extraction. Consider conservative treatment if only low grade infection or skin erosion present; in case of recurrence extract leads

Non-functional leads

Patent venous system: abandon dysfunctional leads, insert new leads ipsilaterally

Occluded venous system: extraction of a non-functional lead and insertion of new leads through exchange procedure ipsilaterally

\section{Thrombotic complications}

Vena cava superior syndrome: consider extraction of non-functional lead and dilatation and stenting of vena cava obstruction

Pulmonary emboli: oral anticoagulation, lead extraction only if embolisation persists

Accufix and Encor leads

Intact retention wire: serial fluoroscopy

Suspected fracture: lead extraction if longer life expectancy and low risk of extraction, else serial fluoroscopy

Protruding or migrated retention wire: lead extraction, if high risk of extraction decide on case by case basis

Miscellaneous

Chronically implanted left ventricular endocardial leads: anticoagulation, surgical extraction if recurrent embolisation

Lead related tricuspid valve insufficiency: no proven benefit of lead extraction

have found significant new regurgitation jets after ventricular lead extraction with a laser sheath in four of 14 consecutive procedures, as a result of direct injury to the tricuspid valve leaflets. ${ }^{54}$

Arrhythmia is rarely an indication for extraction and most probably results from severed or free floating lead segments. ${ }^{45}$

\section{Conclusions}

Current intravascular extraction techniques are effective for extraction of pacemaker leads. However, there are still complications to be taken into account and there is a clear learning curve. ${ }^{72}$ Published reports provide solid support in favour of lead extraction in cases of infectious complications. Lead extraction as primary treatment, even for localised infections, will result in the best opportunity to cure the infection and prevent systemic complications. The indications for lead extraction are summarised in table 2 .

In contrast, although there is a tendency to extract all malfunctioning superfluous leads during revision, the current complication rate of endovascular extraction techniques still outweighs the small risk of leaving the leads properly secured in the patient. The outcome of lead extraction of Accufix or Encor leads shows that, although various lead related complications might have been prevented, the risk of indiscriminate extraction can outweigh the inherent risk of the targeted complication. Therefore the possibility of extracting a lead may not necessarily be accompanied by an indication for lead extraction.

1 Meyers MR, Parsonnet V, Bernstein AD. Extraction of implanted transvenous pacing leads: a review of a persistent clinical problem. Am Heart f 1991;121:881-8.

2 Byrd CL, Schwartz SJ, Hedin N. Lead extraction. Indications and techniques. Cardiol Clin 1992;10:735-48.

3 Love CJ, Wilkoff BL, Byrd CL, et al. Recommendations for extraction of chronically implanted transvenous pacing and defibrillator leads: indications, facilities, training. North defibrillator leads: indications, facilities, training. North American Society of Pacing and Electrophysiology lead
extraction conference faculty. Pacing Clin Electrophysiol 2000;23:544-51.
4 Byrd CL, Schwartz SJ, Hedin NB, et al. Intravascular lead Byrd CL, Schwartz SJ, Hedin NB, et al. Intravascular lead extraction using locking stylets

5 Fearnot NE, Smith HJ, Goode LB, et al. Intravascular lead extraction using locking stylets, sheaths, and other techniques. Pacing Clin Electrophysiol 1990;13:1864-70.

6 Alt E, Neuzner J, Binner L, et al. Three-year experience with a stylet for lead extraction: a multicenter study. Pacing Clin Electrophysiol 1996;19:18-25.

7 Bracke FA, Meijer A, van Gelder B. Learning curve characteristics of pacing lead extraction with a laser sheath. Pacing Clin Electrophysiol 1998;21:2309-13.

8 Wilkoff BL, Byrd CL, Love CJ, et al. Pacemaker lead extraction with the laser sheath: results of the pacing lead extraction with the excimer sheath (PLEXES) trial. $\mathcal{F}$ Am Coll Cardiol 1999;33:1671-6.

9 Kennergren C. First European experience using excimer laser for the extraction of permanent pacemaker leads. Paclaser for the extraction of permanent pace
ing Clin Electrophysiol 1998;21:268-70.

10 Reiser C, Byrd CL, Wilkoff BL, et al. Pacing lead extraction with the Excimer sheath trial: final report [abstract]. Pacing Clin Electrophysiol 1998;22:708.

11 Smith HJ, Fearnot NE, Byrd CL, et al. Five years experience with intravascular lead extraction. US Lead Extraction Database. Pacing Clin Electrophysiol 1994;17:2016-20.

12 Byrd CL, Wilkoff BL, Love CJ, et al. Intravascular extraction of problematic or infected permanent pacemaker leads: 1994-1996. US Extraction Database, MED Institute. Pacing Clin Electrophysiol 1999;22:1348-57.

13 Lewis AB, Hayes DL, Holmes DRJ, et al. Update on infections involving permanent pacemakers. Characterization and management. F Thorac Cardiovasc Surg 1985;89:758-63.

14 Molina JE. Undertreatment and overtreatment of patients with infected antiarrhythmic implantable devices. Ann Thorac Surg 1997;63:504-9.

15 Brodman R, Frame R, Andrews C, et al. Removal of infected transvenous leads requiring cardiopulmonary bypass or inflow occlusion. F Thorac Cardiovasc Surg 1992;103:649-54.

16 Klug D, Lacroix D, Savoye C, et al. Systemic infection related to endocarditis on pacemaker leads: clinical presen tation and management. Circulation 1997;95:2098-107.

17 Hurst LN, Evans HB, Windle B, et al. The salvage of infected cardiac pacemaker pockets using a closed irrigation system. Pacing Clin Electrophysiol 1986;9:785-92.

18 Garcia-Rinaldi R, Revuelta JM, Bonnington L, et al. The exposed cardiac pacemaker. Treatment by subfascial pocket relocation. F Thorac Cardiovasc Surg 1985;89:136-41.

19 Harjula A, Jarvinen A, Virtanen KS, et al. Pacemaker infections - treatment with total or partial pacemaker

20 Vogt PR, Sagdic K, Lachat M, et al. Surgical management of infected permanent transvenous pacemaker systems: ten year experience. 7 Card Surg 1996;11:180-6.

21 Parry G, Goudevenos J, Jameson S, et al. Complications associated with retained pacemaker leads. Pacing Clin Elecassociated with retained pacer

22 Rettig G, Doenecke P, Sen S, et al. Complications with retained transvenous pacemaker electrodes. Am Heart $\mathcal{F}$ 1979;98:587-94.

23 Cacoub P, Leprince P, Nataf P, et al. Pacemaker infective endocarditis. Am $\mathcal{F}$ Cardiol 1998;82:480-4.

24 Bohm A, Banyai F, Preda I, The treatment of septicemia in pacemaker patients. Pacing Clin Electrophysiol 1996;19: 1105-11.

25 Furman S, Behrens M, Andrews C, et al. Retained pacemaker leads. F Thorac Cardiovasc Surg 1987;94:770-2.

26 De Cock CC, Vinkers M, Van Campe LC, et al. Long-term outcome of patients with multiple $(>$ or $=3$ ) noninfected transvenous leads: a clinical and echocardiographic study. Pransvenous leads: a clinical and echocar

27 Balau J, Buysch KH, Marx E, et al. Thrombose der vena subclavia nach transvenöser schrittmacherimplantation. subclavia nach transve
Radiologe 1971;11:50-3.

28 Marx E, Schulte HD, Balau J, et al. Phlebographische und klinische Fruh- und Spatbefunde bei transvenos implantierten Schrittmacherelektroden. Z Kreislaufforsch 1972;61: 115-23.

29 Stoney WS, Addlestone RB, Alford WCJ, et al. The incidence of venous thrombosis following long-term transvenous pacing. Ann Thorac Surg 1976;22:166-70.

30 Mitrovic V, Thormann J, Schlepper M, et al. Thrombotic complications with pacemakers. Int f Cardiol 1983;2:363-74.

31 Antonelli D, Turgeman Y, Kaveh Z, et al. Short-term thrombosis after transvenous permanent pacemaker inserthrombosis after transvenous permanent pace

32 Pauletti M, Di Ricco G, Solfanelli S, et al. Venous obstruction in permanent pacemaker patients: an isotopic study. tion in permanent pacemaker patients:
Pacing Clin Electrophysiol 1981;4:36-42.

33 Zuber M, Huber P, Fricker U, et al. Assessment of the subclavian vein in patients with transvenous pacemaker leads. Pacing Clin Electrophysiol 1998;21:2621-30.

34 Goudevenos JA, Reid PG, Adams PC, et al. Pacemakerinduced superior vena cava syndrome: report of four cases and review of the literature. Pacing Clin Electrophysiol 1989; 12:1890-5

35 Chamorro H, Rao G, Wholey MH. Superior vena cava syndrome: a complication of transvenous pacemaker implantation. Radiology 1978;126:377-8.

36 Mazzetti H, Dussaut A, Tentori C, et al. Superior vena cava occlusion and/or syndrome related to pacemaker leads. Am Heart f 1993;125:831-7.

37 Zerbe F, Ponizynski A, Dyszkiewicz W, et al. Functionless retained pacing leads in the cardiovascular system. A complication of pacemaker treatment. Br Heart f 1985;54:76-9. 
38 Ing FF, Mullins CE, Grifka RG, et al. Stent dilation of superior vena cava and innominate vein obstructions permits transvenous pacing lead implantation. Pacing Clin Electrophysiol 1998;21:1517-30.

39 Bracke FA, van Gelder LM, Sreeram N, et al. Exchange of pacing or defibrillator leads following laser sheath extraction of non-functional leads in patients with ipsilatera obstructed venous access. Heart 2000;83:E12.

40 Seeger W, Scherer K. Asymptomatic pulmonary embolism following pacemaker implantation. Pacing Clin Electrophysiol 1986;9:196-9.

41 Porath A, Avnun L, Hirsch M, et al. Right atrial thrombus and recurrent pulmonary emboli secondary to permanent cardiac pacing - a case report and short review of literature. Angiology 1987;38:627-30.

42 Kinney EL, Allen RP, Weidner WA, et al. Recurrent pulmonary emboli secondary to right atrial thrombus around a permanent pacing catheter: a case report and review of the permanent pacing catheter: a case report and review

43 Pasquariello JL, Hariman RJ, Yudelman IM, et al. Recurrent pulmonary embolization following implantation of transpulmonary embolization following implantation of trans-
venous pacemaker. Pacing Clin Electrophysiol 1984;7:790-3.

44 de Vries H, Iversen S, Zimmermann W, et al. Chronic de Vries $\mathrm{H}$, Iversen S, Zimmermann W, et al. Chronic
thromboembolic cor pulmonale in pacemaker-associated right atrial thrombi. Pulmonary thromboendarterectomy with removal of the electrodes as a life-saving measure. Dtsch Med Wochenschr 1991;116:294-8.

45 Friedman SA, Berger N, Cerruti MM, et al. Venous thrombosis and permanent cardiac pacing. Am Heart f 1973;85:531-3.

46 Kawanishi DT, Brinker JA, Reeves R, et al. Cumulative hazard analysis of J-wire fracture in the Accufix series of atrial permanent pacemaker leads. Pacing Clin Electrophysiol 1998;21:2322-6.
47 Kawanishi DT, Brinker JA, Reeves R, et al. Kaplan-Meier analysis of freedom from extraction or death in patients analysis of freedom from extraction or death in patients with an accufix $J$ retention wire atrial permanent pacemaker lead: a potential management tool. Pacing Clin Electrophysiol 1998;21:2318-21.

48 Kawanishi DT, Brinker JA, Reeves R, et al. Spontaneous versus extraction related injuries associated with accufix J-wire atrial pacemaker lead: tracking changes in patient management. Pacing Clin Electrophysiol 1998;21:2314-7.

49 Liebold A, Aebert H, Muscholl M, et al. Cerebral embolism due to left ventricular pacemaker lead: removal with cardiopulmonary bypass. Pacing Clin Electrophysiol 1994; 17:2353-5.

50 Ross WB, Mohiuddin SM, Pagano T, et al. Malposition of a transvenous cardiac electrode associated with amaurosis fugax. Pacing Clin Electrophysiol 1983;6:119-24.

51 Schiavone WA, Castle LW, Salcedo E, et al. Amaurosis fugax in a patient with a left ventricular endocardial pacemaker. Pacing Clin Electrophysiol 1984;7:288-92.

52 Trohman RG, Wilkoff BL, Byrne T, et al. Successful percutaneous extraction of a chronic left ventricular pacing lead. taneous extraction of a chronic left ventricular
Pacing Clin Electrophysiol 1991;14:1448-51.

53 Paniagua D, Aldrich HR, Lieberman EH, et al. Increased prevalence of significant tricuspid regurgitation in patients with transvenous pacemakers leads. Am F Cardiol 1998;82: 1130-2, A9.

54 Bracke FA, Botman CJ, Peels CH, et al. Transoesophageal echocardiographic evaluation of the tricuspid valve during laser sheath extraction of pacemaker and ICD leads [abstract]. Pacing Clin Electrophysiol 1999;22:A108.

55 Frandsen F, Oxhoj H, Nielsen B. Entrapment of a tined pacemaker electrode in the tricuspid valve. A case report. Pacing Clin Electrophysiol 1990;13:1082-3.

\section{IMAGES IN CARDIOLOGY}

\section{Kawasaki's disease}

A 27 year old woman was admitted with a history of typical crescendo angina pectoris for 10 days. There were no abnormal findings at clinical examination. Consecutive ECGs showed symmetric negative $\mathrm{T}$ waves in precordial leads. Troponin I concentration was $2.5 \mathrm{ng} / \mathrm{ml}$ (normal range $0-1.6 \mathrm{ng} / \mathrm{ml}$ ). There was no evidence of systemic inflammation in laboratory investigations. The patient's coronary risk factors comprised smoking (one pack a week) and hypercholesterolaemia (total cholesterol $243 \mathrm{mg} / \mathrm{dl}(6.28 \mathrm{mmol} / \mathrm{l}))$.

Echocardiography showed normal left ventricular wall motion and heart valves. Coronary angiography was undertaken and revealed severe three vessel coronary artery disease with an occluded aneurysm of the right coronary artery adjacent to the ostium, and a huge calcified aneurysm of the left main coronary artery, including the proximal parts of the left anterior descending and the circumflex coronary artery (right). The distal parts of these two arteries were significantly altered with dilated and stenotic lesions. Using duplex sonography and angiography, aneurysms of the large arteries of the upper and the lower limbs could be excluded.

An extensive medical history revealed that 12 years previously the patient had experienced a severe, prolonged, unexplained febrile illness,

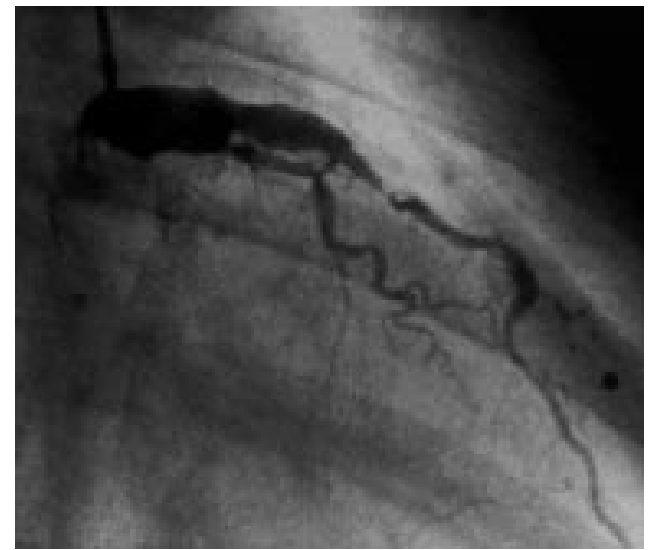

with a maculopapular rash of the trunk, erythema followed by desquamation of the hands, sinusitis, cardiomegaly, serous meningitis, and cervical lymphadenopathy. Therefore a retrospective diagnosis of Kawasaki's disease was made.

After a successful aortocoronary bypass operation the patient made an uneventful recovery, and was discharged on aspirin, a statin, and a $\beta$ blocker.

THOMAS WEBER HERBERT MAYR

BERND EBER webertom@liwest.at 